https://helda.helsinki.fi

\title{
The development of ethical guidelines for nurses' collegiality using the Delphi method
}

\section{Kangasniemi, Mari}

2017-08

Kangasniemi , M , Arala , K, Becker , E , Suutarla , A , Haapa , T \& Korhonen , A 2017 , ' The development of ethical guidelines for nurses' collegiality using the Delphi method ' , Nursing Ethics, vol. 24 , no. 5 , pp. 538-555 . https://doi.org/10.1177/0969733015617342

http://hdl.handle.net/10138/297923

https://doi.org/10.1177/0969733015617342

publishedVersion

Downloaded from Helda, University of Helsinki institutional repository.

This is an electronic reprint of the original article.

This reprint may differ from the original in pagination and typographic detail.

Please cite the original version. 
The development of ethical guidelines for nurses' collegiality using the Delphi method

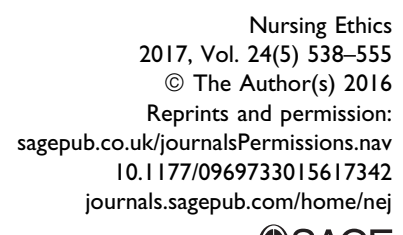

(9)AGE

\title{
Mari Kangasniemi
}

University of Eastern Finland, Finland

\section{Katariina Arala}

University Hospital, Southern Finland

\section{Eve Becker}

Tehy, Finland

\section{Anna Suutarla}

Finnish Nurses' Association, Finland

\section{Toni Haapa}

University of Tampere, Finland; Hospital District of Helsinki and Uusimaa, Finland; University Hospital, Southern Finland

\section{Anne Korhonen}

Oulu University Hospital, Northern Finland

\begin{abstract}
Background: Nurses' collegiality is topical because patient care is complicated, requiring shared knowledge and working methods. Nurses' collaboration has been supported by a number of different working models, but there has been less focus on ethics.

Aim: This study aimed to develop nurses' collegiality guidelines using the Delphi method.

Method: Two online panels of Finnish experts, with 35 and 40 members, used the four-step Delphi method in December 2013 and January 2014. They reformulated the items of nurses' collegiality identified by the literature and rated based on validity and importance. Content analysis and descriptive statistical methods were used to analyze the data, and the nurses' collegiality guidelines were formulated.

Ethical considerations: Organizational approval was received, and an informed consent was obtained from all participants. Information about the voluntary nature of participation was provided.

Results: During the first Delphi panel round, a number of items were reformulated and added, resulting in 32 reformulated items. As a result of the second round, 8 of the 32 items scored an agreement rate of more than $75 \%$, with the most rated item being collegiality means that professionals respect each other. The item with second highest rating was collegiality has a common objective: what is best for patients, followed by the third highest which was professional ethics is the basis of collegiality.
\end{abstract}

Corresponding author: Mari Kangasniemi, Department of Nursing Science, Faculty of Health Sciences, University of Eastern Finland, P.O. Box 1627, 7021I Kuopio, Finland.

Email: mari.kangasniemi@uef.fi 
Conclusion: Nurses' collegiality and its content are well recognized in clinical practice but seldom studied. Collegiality can be supported by guidelines, and nurses working in clinical practice, together with teachers and managers, have shared responsibilities to support and develop it. More research in different nursing environments is needed to improve understanding of the content and practice of nursing collegiality.

\section{Keywords \\ Collegiality, Delphi method, ethics, guidelines, nursing}

\section{Introduction}

In Spring 2013, registered nurses working at the (University Hospital in Southern Finland) University Hospital approached the Finnish Nurses' Association (FNA) and asked them whether they could help them by creating collegiality guidelines for their work. They said that they felt that the existence of such guidelines would help them to be more collegial toward each other in their everyday work. This prompted the FNA to establish a working group to investigate the best ways of supporting nurses' ethical practices.

In addition to concerns that face nurses in their professional practice, the question of nurses' collegiality is highly topical. Nurses work under multi-dimensional pressures, and their ethical working is threatened due to internal and external factors, such as time pressures and high workloads. ${ }^{1-4}$ These pressures mean that nurses have to not only support each other but also ensure that colleagues are not overburdened by work they are unable to finish. ${ }^{5}$ Moral distress has increased in recent years, ${ }^{6}$ and the need for collegial support between nurses is obvious.

Over the last decades, collegiality has been recognized in several professional journals ${ }^{7,8}$ and noted by editors. ${ }^{9}$ Collegiality is important for good communication ${ }^{10}$ and ethical collaboration with colleagues ${ }^{1}$ and affects how they treat each other. ${ }^{11,12}$ In addition, it has been linked to increasing patient safety ${ }^{8}$ and helping to bridge the gap between generations. ${ }^{7,13}$

Despite being topical, studies on nurses' collegiality are relatively rare. ${ }^{14}$ Professional codes created by nursing associations have recognized nurses' collegiality and mutual respect. ${ }^{15-19}$ According to the International Council of Nurses (ICN), ${ }^{19}$ nurses are required to conduct themselves in ways that reflect well on the profession and enhance public confidence. The American Nurses Association (ANA) ${ }^{15}$ compels nurses to treat colleagues, students, and patients with dignity, but separate or focused collegial guidelines do not exist. Because of the fragmented understanding of collegiality in existing studies and the lack of previous guidelines, the FNA created their own collegiality guidelines. The aim of this study was to describe the development of those nurses' collegiality guidelines using the four-step Delphi method.

\section{Collegiality in previous literature and the development of ethical guidelines}

\section{Collegiality as a value of professional ethics}

Collegiality has been defined as a value of professional ethics referring to the mutual and equal relationship between nurses. ${ }^{14,20,21}$ The aim of professional ethics is to guide nurses to achieve their purpose in society. $^{22-25}$ Professional ethics is guided by legislation ${ }^{12,26,27}$ and professional codes. ${ }^{11,28-30}$ Professional codes incorporate the professional values of the individual profession, ${ }^{11,12,31}$ and the aim of ethical codes is to support and guide nurses in clinical care. ${ }^{11,12,31-33}$ Professional ethics' values make it easier for the general public to understand the work of nurses ${ }^{25}$ and also provide nurses with an ethically accepted manner of working. 


\section{The content of collegiality}

The core of collegiality in nursing ethics is the shared goal of profession, ${ }^{20,34,35}$ which is to provide patients with the best care possible. ${ }^{34,36-38}$ It is based on the professional ${ }^{35,38}$ and personal ${ }^{34,35}$ values of a nurse. Collegiality is non-hierarchical ${ }^{35,39}$ and relates to the mutual relationship between nurses, reflecting values such as equality, ${ }^{20,21,35,40}{\text { justice, } \text { trust }^{35,40,41} \text { and respect. }}^{20,21,35,40,42}$

Collegiality is based on open, confidential, emphatic, and dialogic communication, ${ }^{20,34,35,40,42}$ and it is demonstrated in autonomy and decision-making. ${ }^{35,38,40}$ In addition, it has been recognized that advocating on behalf of colleagues and intervening when things go wrong are expressions of collegiality. ${ }^{37,43}$ Collegiality is also connected to organizational support ${ }^{20,40}$ and the conditions of the society in which the care is being provided. ${ }^{34}$

The need for collegial working among nurses has been highlighted because of the nature of their work. Nurses work closely with patients and can be responsible for their long-term care. ${ }^{39}$ They also have the main responsibility for ensuring the critical care links are maintained, providing information to colleagues during sift handovers and managing patient transfers between units and institutions. ${ }^{34,36,39}$

\section{The meaning and development of guidelines for nursing ethical practice}

The aim of ethical guidelines in nursing is to support and advice nurses in clinical practice. Currently, the evidence-based approach is widely used with the development of clinical and ethical guidelines. ${ }^{44,45}$ In previous studies, the development of guidelines was based on systematic reviews concerning previous knowledge, ${ }^{45}$ existing legislation, and the recommendations or ethical guidelines. ${ }^{32,44}$ That knowledge has been combined with the empirical knowledge of users ${ }^{45}$ as well as expert opinions. ${ }^{44,46}$ The use of empirical knowledge has been an opportunity to contribute to poor, or scarce, previous knowledge. ${ }^{45}$ The challenge with developing guidelines has been to formulate them so that they are practical and simple but as precise and exact as possible. ${ }^{47}$

In recent studies, the Delphi method has proved to be an established method for developing clinical nursing guidelines ${ }^{47-55}$ and has been used in the field of ethics in relation to nursing ethics education ${ }^{56}$ and human dignity. ${ }^{46}$

\section{Aim}

The aim of this study was to develop nurses' collegiality guidelines through a systematic review and with the assistance of two online Delphi panels. An ultimate aim was to create guidelines that could support nurses' collegiality in their clinical practice and guidelines for managers and teachers to help them create the right circumstances for nurses' collegiality.

\section{Methods}

\section{Research design}

The Delphi method ${ }^{57-59}$ was used to seek expert perceptions and agreement on nurses' collegiality. That process included four steps: (a) identifying the items involved in nurses' collegiality, (b) forming the expert panel, (c) conducting two rounds of an online survey with Finnish experts, and (d) formulating the statements in the final guidelines (Figure 1). The process was conducted by a research group, which consisted of six experts in different nursing fields, including clinical nursing, management, teaching, research, and members of the nursing association responsible for liaising with profession. 


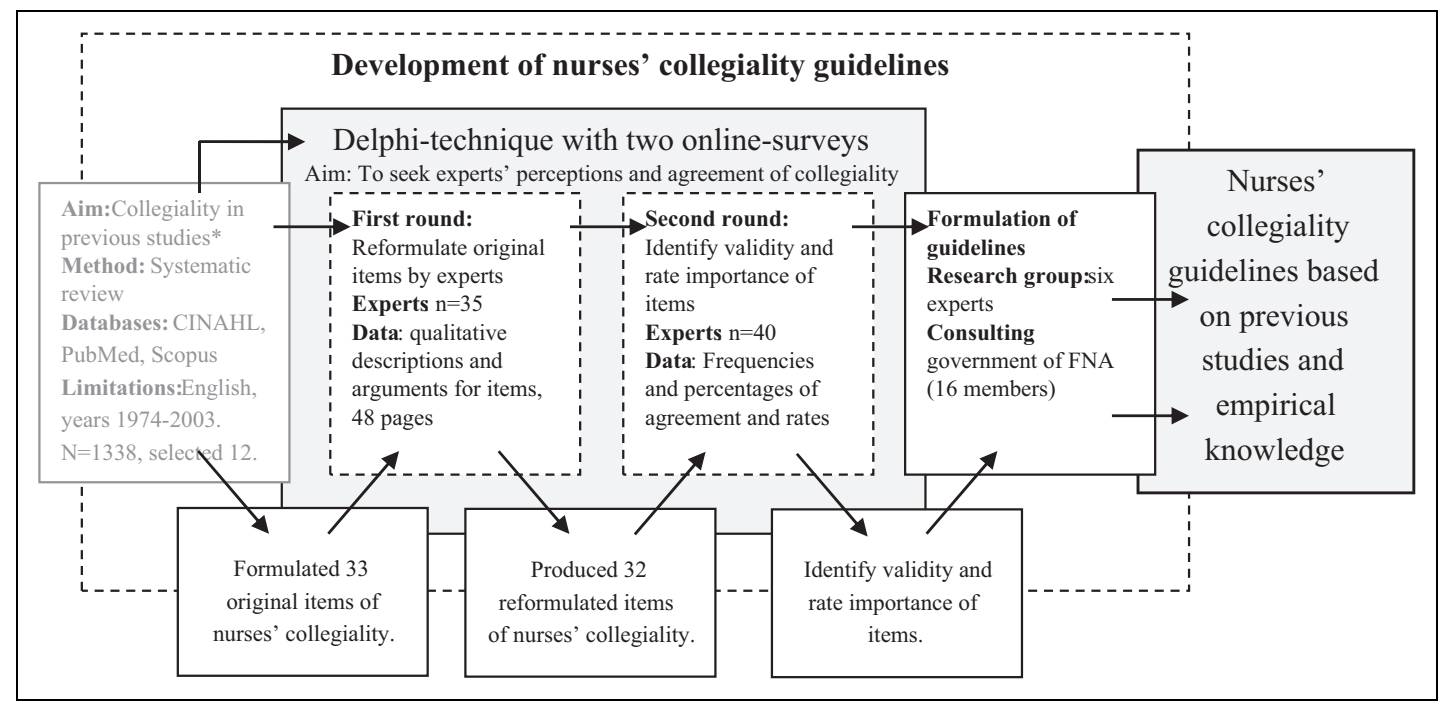

Figure I. Flow chart of development process involved in the nurses' collegiality guidelines. *This step has been reported in Kangasniemi et al. 2015. ${ }^{14}$

Step I: identifying the items of nurses' collegiality. The first step of the Delphi process was to identify items related to nurses' collegiality. The working definition of collegiality was based on previous knowledge, and the research team conducted a systematic review of the literature using relevant search process ${ }^{14}$ (Figure 1). Based on the working definition (presented previously in this paper in the section of framework), the research team identified the content of collegiality and formulated items during discussion in several meetings. The team formulated 33 original items, and each one represented a different element of collegiality. Based on their similarities and differences, elements were categorized into four main themes: (a) the ethical basis of collegiality, (b) the emergence of collegiality in clinical practice, (c) collegiality in the organization, and (d) collegiality and society (Table 1).

Step 2: formulation of expert panel. The second step was to form the expert panel, and the target group was experts who were experienced in nurses' collegiality and would volunteer to take part. They were recruited in collaboration with the FNA. After we received organizational approval from the FNA, an invitation to participate in the Delphi panel was sent to members of the Association as part of a monthly electronic newsletter in November 2013. In that year, there were 81,500 registered nurses in Finland, 50,000 were members of the FNA and approximately 31,100 subscribed to the monthly newsletters. The invitation letter was also published on the Association's website and a personal invitation was sent to the main office of the Finnish Medical Association (FMA).

The invitation letter contained information about the aim of the study and the two-round design of the Delphi process. Participants were encouraged to participate in both rounds. The inclusion criteria for participation were professional education, working as a nurse, manager, researcher, teacher or physician, and willingness to participate. The fulfillment of the inclusion criteria was based on the participants' self-evaluation.

Step 3: conducting two-round online panels. The third step was conducting the two-round Delphi panel using Webropol 2.0 software. In total, 82 members of the FNA and one member of the FMA agreed to take part 


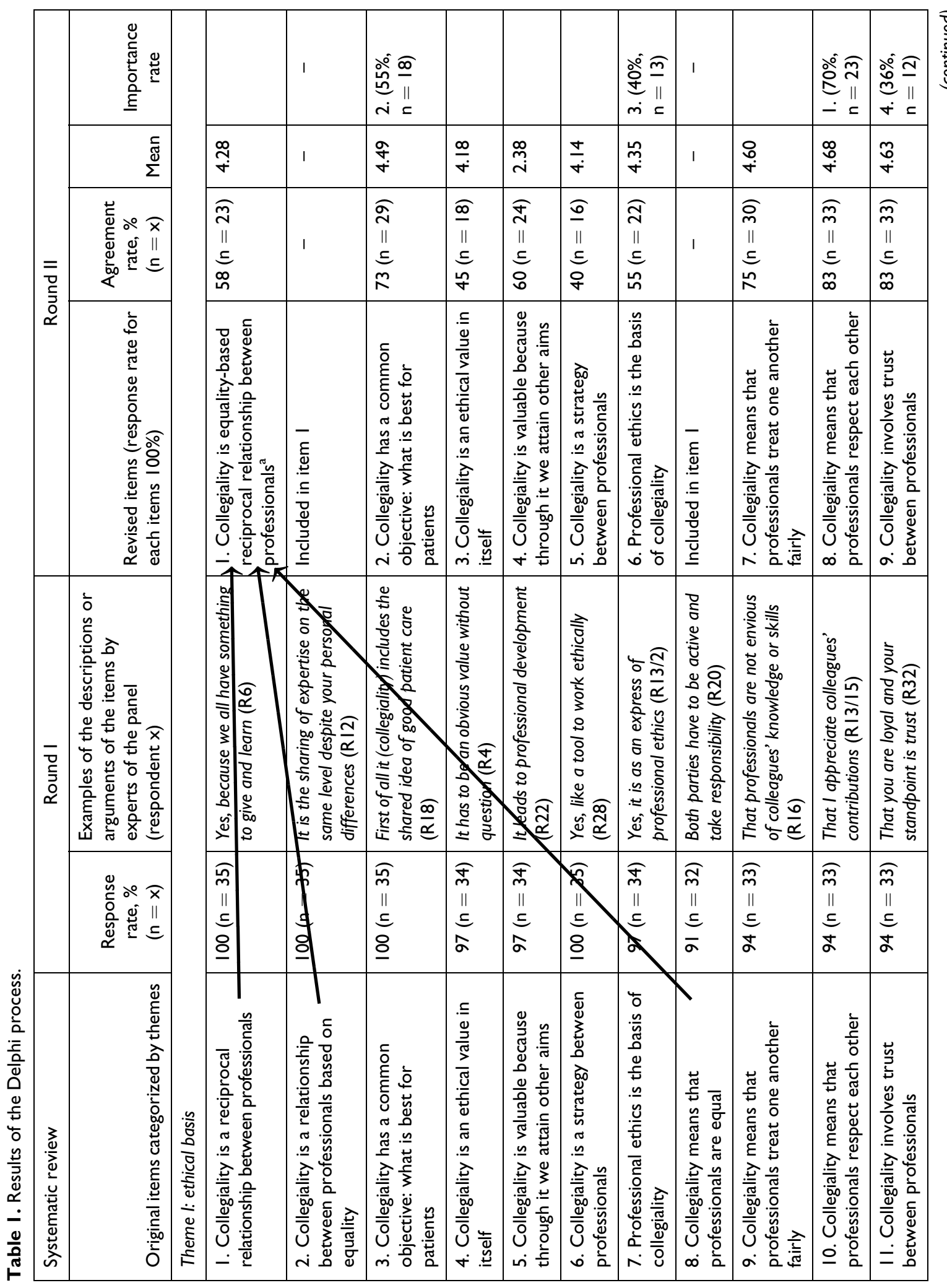




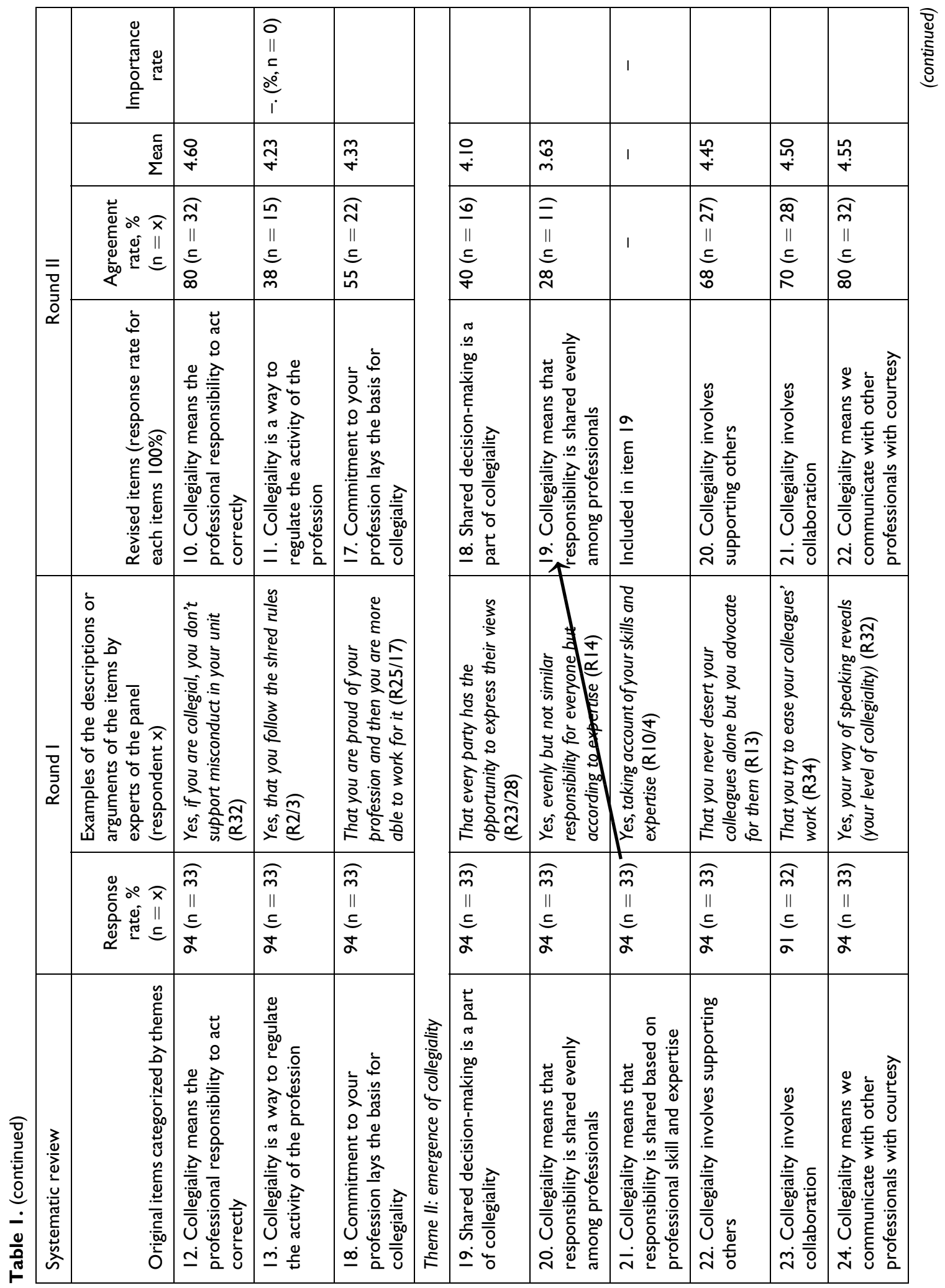




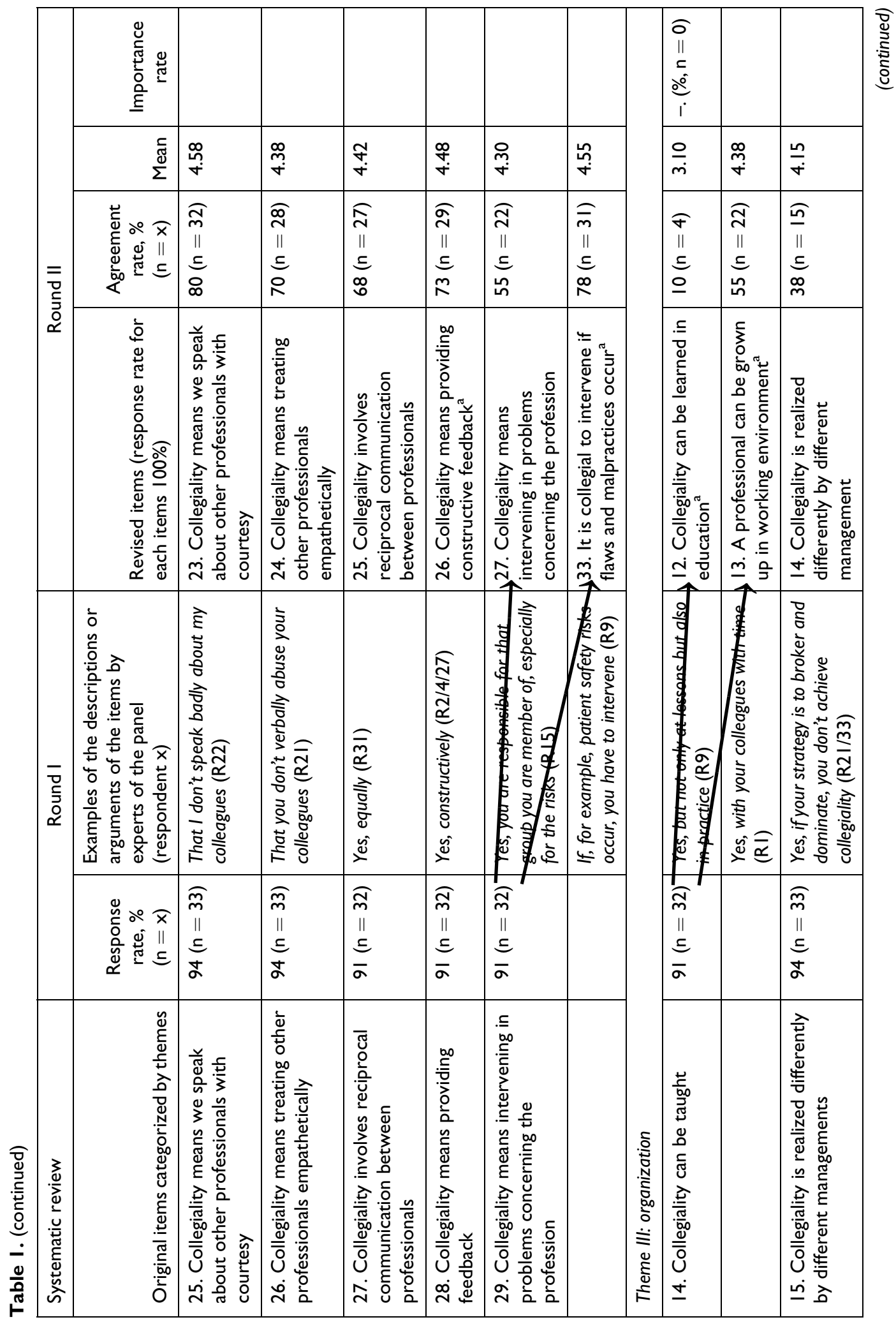




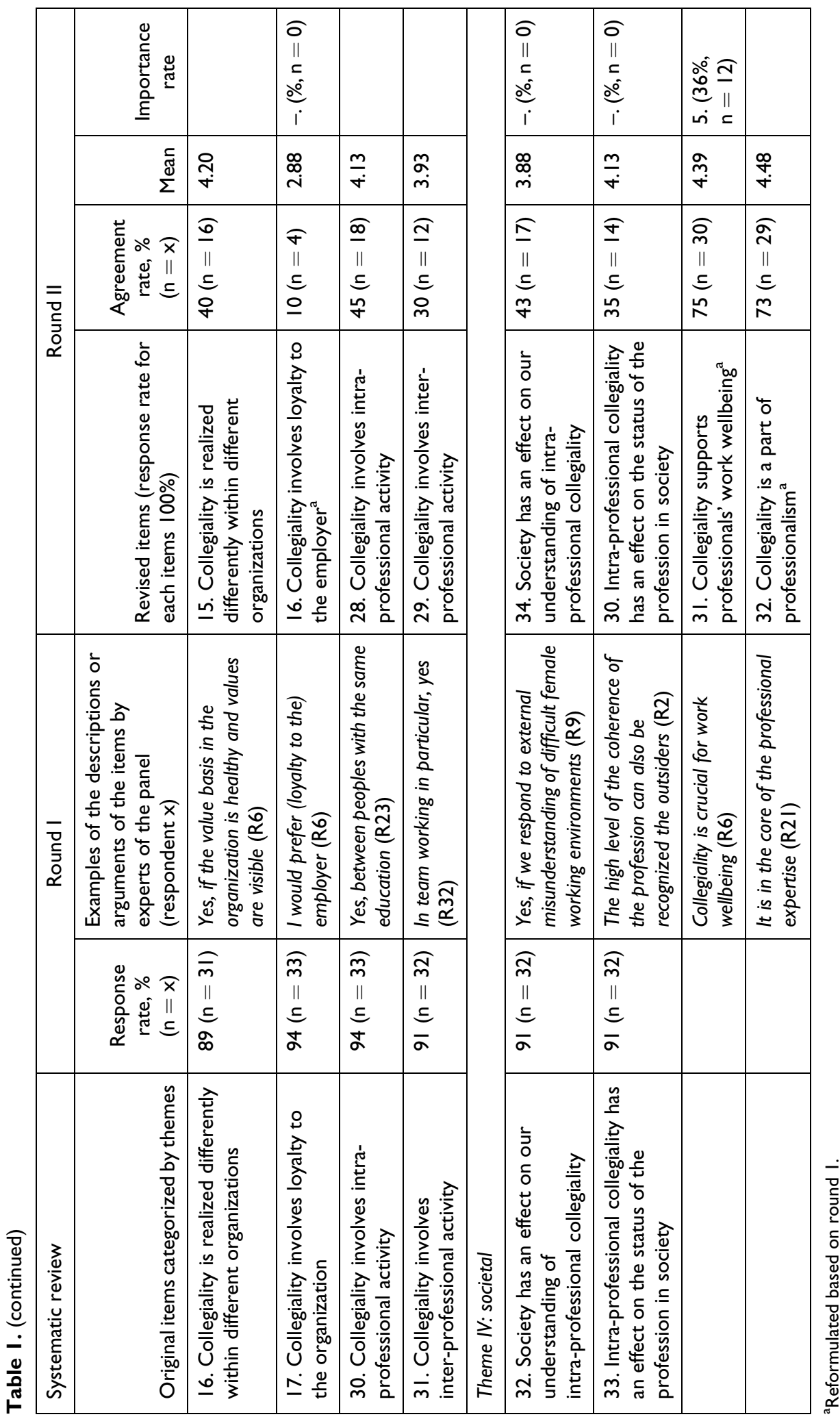


and sent their e-mail addresses to the researcher (author E.B.). During the first round, the link for electronic Webropol questionnaire was sent to all voluntary participants in December 2013, with a response time of 9 days, and the second round was sent in January 2014, with a response time of 14 days. The Webropol questionnaire consisted of a section containing background information with four questions about age, sex, years of working experience, and current working position, together with the items to be explored in each rounds.

The aim of the first round was to validate or eventually reformulate original items with empirical, qualitative knowledge. The first-round participants were invited to make comments about what they thought about the items presented and to explain their perceptions. The first round consisted of 33 original items with space for a 4000-character response and guiding text that asked them for their views on the statement.

A total of 35 participants took part in the first round, producing 48 A4 pages of contents when printed in 12 pt Calibri and 1.15 line spacing. The data ranged from short sentences, a couple of words, to longer descriptions of the content or arguments. During the first phase of the analysis, the response rate for each item was calculated and described as frequencies and percentages. After that, the data were analyzed by applying deductive-inductive qualitative content analysis, ${ }^{60}$ in order to find out the experts' perceptions of the items and the possible needs to reformulate them. Agreement was not evaluated in this phase. The 33 original items were used as a deductive framework for analysis. In the first phase, data were read several times in order to understand the content. After that, the analysis unit - a word, couple of word, or sentence - was defined and the content under each original item was coded according to them. The reading of the data and the definition of the analysis unit were conducted by all members of the research group. One of the researchers (K.A.) conducted the deductive coding and initially categorized the data. After that, the content under each item was discussed by the whole research group in order to reformulate items (Table 1). As a result of the analysis, nine of the items were reformulated and two new items were inductively created. Reformulation was conducted in agreement with all members of the research group.

The aim of the second round was to identify the validity of the items and rate their importance based on empirical knowledge. The second round consisted of the remaining 32 reformulated items. Participants were sent reformulated items and asked to identify the validity of the items in nursing practice, using a 5-point Likert scale, from $1=$ strongly disagreed to $5=$ strongly agree. They were also asked to rank the five most important items. The data from the second round were analyzed by descriptive statistical methods using frequencies and presents of the agreement and were analyzed using SPSS for Windows (14.0, SPSS Inc., 2005). The required level of agreement was defined in advance, with a consensus of $75 \%$ on each indicator being sought to provide adequate discrimination between the indicators retained for further rounds. ${ }^{61,62}$ A total of 40 participants responded in the second round.

Step 4: formulation of collegiality guidelines. The fourth step was for the research group to formulate and finalize collegiality guidelines. The aim of this step was to do this based on the systematic review and empirical knowledge, but to ensure that the guidelines were sufficiently operational, clear, and unambiguous for clinical use. ${ }^{47}$ All the reformulated items, and the results of the second-round validity identification and ranking, were considered by the research group. The content for guidelines was driven from items based on the systematic review, their reformulation by panelists, and agreement on their validity by panelists. ${ }^{45}$ They tried to keep the wording as close as possible to the original items. Original items were grouped in themes based on their similarities and differences, and four main themes remained. The process of development and the final version of the guidelines were presented to the Governors of the FNA, and based on their agreement, a final version was accepted and published for free download as a PDF (Table 2). 
Table 2. Nurses' collegiality guidelines by Finnish Nurses' Association. ${ }^{72}$

Purpose of guidelines

The purpose of collegiality guidelines is to support collegiality among nurses ${ }^{\mathrm{a}}$ in their daily work. The guidelines obligate us to work collegially with one another.

What is collegiality?

Our collegiality as nurses in an equal and reciprocal relationship between members of the profession. It supports our professional work and aims to achieve a common objective - the best patient care possible. Collegiality influences the profession's internal cohesion and status in society.

Collegiality is based on professional ethics

- We respect and esteem our colleagues.

- We treat our colleagues fairly.

- We trust our colleagues and are trustworthy ourselves.

- We comprise a unified profession.
Communication is collegial

- We speak about our colleagues and to our colleagues respectfully and politely.

- Communication between us is open, honest, and confidential.

- We give and receive constructive feedback.

- We defend and support colleagues in unfair or difficult situations.

- As nurses, we create a working community in which grievances and conflicts can be dealt with.

Cooperation strengthens skills

- We recognize and acknowledge our colleagues' skills.

- We consult with our colleagues on a reciprocal basis.

- We share responsibility, decision-making, and duties equally and fairly.

- We support our colleagues in work tasks and decision-making.

- It is our responsibility as nurses to intervene in a colleague's actions, if they pose a threat to patient safety.
Everyone is responsible for collegiality

- We are responsible by our own example for the collegiality of the profession in and outside the workplace.

- Our nursing managers are responsible for creating structures that support collegiality.

- Our profession is responsible for teaching and fostering collegiality.

${ }^{\text {a}}$ The term nurse is used to refer to a registered nurse, public health nurse, midwife or paramedic (with bachelor's degree).

\section{Ethical considerations}

According to Finnish law, this type of research does not need approval from an official research ethics committee. ${ }^{64}$ Organizational approval was received from the FNA for the recruitment process. Informed consent was obtained from all participants, and information about the voluntary nature of participation was provided. $^{65}$

\section{Findings}

A total of 35 experts took part in the first round and 33 of these also took part in the second round, where they were joined by 7 new experts, making total of 40 second-round participants. The experts in both rounds were mainly middle-aged, female, registered nurses, with a mean of 20 years' nursing experience, ranging from students to those who had been in the profession for 35 years. The other participants were 10 nursing managers in the first round and 13 in the second, one nursing teacher in both rounds, two clinical nurse specialists in the first round and four in the second round, one researcher in both round, and one physician in the first round (Table 3). 
Table 3. Description of experts in the first and second rounds.

\begin{tabular}{lcc}
\hline & First round $(\mathrm{n}=35)$ & Second round $(\mathrm{n}=40)$ \\
\hline Response rate (\%) & 42.68 & 48.78 \\
Age (years), mean (min-max, SD) & $44.29(20.00-59.00,14.14)$ & $49.00(24.00-66.00,29.70)$ \\
Gender, $\mathrm{n}(\%)$ & & \\
$\quad$ Female & $33(94.28)$ & $37(94.87)$ \\
$\quad$ Male & $2(5.72)$ & $2(5.13)$ \\
Education, $\mathrm{n}(\%)$ & $\mathrm{I}(2.86)$ & $\mathrm{I}(2.50)$ \\
$\quad$ Nursing student & $19(54.29)$ & $20(50.00)$ \\
Registered nurse & $10(28.57)$ & $13(32.50)$ \\
Nursing manager & $\mathrm{I}(2.86)$ & $\mathrm{I}(2.50)$ \\
Nursing teacher & $2(5.70)$ & $4(10.00)$ \\
Clinical nurse specialist & $\mathrm{I}(2.86)$ & $\mathrm{I}(2.50)$ \\
Researcher & $\mathrm{I}(2.86)$ & $0(0.00)$ \\
Physician & $18.83(0.50-35.00,14.14)$ & $23.70(0.00-35.00,24.75)$ \\
Work experience (years), mean (min-max, SD) & &
\end{tabular}

SD: standard deviation.

\section{Round I}

Reformulation of items. In the first round, the percentage of those responding to the 33 original items varied from $31(89 \%)$ to $35(100 \%)$. Based on the participants' descriptions and arguments, nine (24\%) of the items were reformulated and combined and two new items were provided. At the end, 32 reformulated items were produced (Table 1).

Because of repeating and overlapping responses, a number of items were combined, with item 1 created from items 1, 2, and 8 and item 19 created from items 20 and 21 (Table 1). With regard to new item 1, the experts on the panel said that equality influenced reciprocity, but also that reciprocity was based on equality and collegiality represents that kind of relationship:

Without reciprocity collegiality doesn't exist between nurses. (Respondent 24)

It (reciprocity) is a keyword in collegiality, in their equal relationship. (Respondent 17)

In reciprocal, collegial relationship you are equal, despite your differences in work experience or skills. (Respondent 35)

Items 20 and 21 were combined to form new item 19 because experts in the panel linked the content of the items together. They said that collegiality meant that they had different tasks in clinical practice according to their expertise, but the same, shared responsibility (Table 1):

Yes, (in collegiality) responsibility is divided according to tasks and skills and it can vary between nurses. But all nurses who work collegially have a responsibility of their own but also as a shared responsibility (with their colleagues). (Respondent 6)

In two items, expressions were amended based on respondents descriptions (items 16 and 26), and in two cases, the original items (14 and 29) were divided and two more descriptive items were formulated (Table 1). In item 16, respondents pondered that if collegiality included loyalty, this was not directed at an organization but at an employer: 
Collegiality is something between human beings. (Respondent 3)

Not towards an organization, because as an inherent feature of collegiality, reciprocity, wouldn't be possible. But towards your employer, yes, then collegiality can exist. (Respondent 23)

Original item 14, that collegiality could be taught, raised questions about the learning methods and learning environment and was divided into two separate items (Table 1). According to the experts on the panel, collegiality could and should be taught as part of in nursing education and students could learn it theoretically and practice it in their everyday communication with fellow students and teachers. However, respondents highlighted that collegiality could be taught in clinical practice as well, and they described that working environment and their workmates were their main teachers when it came to learning how to be collegial:

Yes, it can be taught, but not only by theoretical lessons but living it in your life. (Respondent 1)

I would say that you learn how to be collegial. (Respondent 7)

A new nurse in the unit will learn how to encounter their colleagues in the right manner. I would like to say that collegiality is transmitted. (Respondent 9)

Finally, two new items were provided based on the panelists' descriptions (Table 1). Item 31, collegiality supports professionals' work wellbeing, means that a collegial way of working creates an atmosphere where you can be a human being, can be seen and heard, and feel motivated to work. Collegiality was seen to empower nurses and prevent work-based fatigue and overloading:

It (collegiality) is not only a question of good patient care; it has to be highlighted so that we are able to work and experience wellbeing at work. (Respondent 22)

Item 32, collegiality is a part of professionalism, was created because experts in the panel not only linked collegiality to ethical issues, but they also saw it as a professional requirement for nurses (Table 1):

For me, collegiality is a core of professionalism. To be collegial is the best thing I can do for my colleague in this current bankruptcy of healthcare. I care for my colleagues. (Respondent 21)

To be a professional, you need others, it (collegiality) is essential and one of the main ideas of the working in healthcare. (Respondent 22)

\section{Round 2}

The response rate for each item in the second round was $100 \%$. The mean of the agreement on all of the items was 4.25 on the 5-point Likert scale, where $1=$ strongly disagreed and $5=$ strongly agreed, and the agreement varied from 2.88 to 4.67 . An agreement rate more than $75 \%$ was recorded for eight items.

The items that most participants agreed on were item 8 , collegiality means that professionals respect each other, with $33(83 \%)$ strongly agreeing and a mean of 4.68 and item 9, collegiality involves trust between professionals, with the same number of strongly agreeing and a mean of 4.63. Other items where more than $75 \%$ of participants strongly agreed concerned fair treatment of colleagues (item 7, $\mathrm{n}=30,75 \%$, mean: 4.60) and responsibility to act correctly (item 10, $\mathrm{n}=32,82 \%$, mean: 4.60 ), courtesy communication with colleagues (item $22, \mathrm{n}=32,82 \%$, mean: 4.55 ) as well as speak about the other colleagues with courtesy (item 23, $\mathrm{n}=32,82 \%$, mean: 4.58). In addition, there was strong agreement about two items that were created in the first round: it is collegial to intervene if flaws and malpractices occur (item 33, $\mathrm{n}=31,78 \%$, mean: 4.55) and collegiality supports work wellbeing (item $31, \mathrm{n}=30,75 \%$, mean: 4.39). 
There were only two items that received an agreement rate of under $25 \%$ because participants did not agree with the statements: collegiality could be learned in education (item 12, $\mathrm{n}=4,10 \%$, mean: 3.10 ) and collegiality was also loyalty toward employees (item $16, \mathrm{n}=4,10 \%$, mean: 2.88 ). Item 16 was the item with the strongest disagreement among participants. Other items that the panel strongly disagreed with included the one that stated that intra-professional collegiality has an effect on the status of the profession in society (item $30, \mathrm{n}=5,13 \%$ ), and collegiality means that responsibility is shared evenly among professionals (item $19, \mathrm{n}=5,13 \%$ ). In general, the number who strongly disagreed with statements varied from 0 to 7 .

According to experts, the five most highly rated items were as follows: collegiality means that professionals respect each other $(\mathrm{n}=23,70 \%)$, collegiality has a common objective: what is best for patients $(\mathrm{n}=18,55 \%)$, professional ethics is the basis of collegiality $(\mathrm{n}=13,40 \%)$, items as collegiality involves trust between professionals $(\mathrm{n}=12,36 \%)$, and collegiality supports professionals' wellbeing at work $(\mathrm{n}=12,36 \%)$. The five least important items identified during the second round concerned collegiality's role to regulate profession internally (item 11), that collegiality can be learned in education (item 12), that collegiality means loyalty toward employer (item 16) and two items concerning the relationship between the profession's collegiality and wider society (items 34 and 30).

\section{Discussion}

Based on our results, the subject and content of nurses' collegiality have rarely been reported in the literature. However, collegiality is one of the moral values based on professional ethics in nursing. It is guided by legislation and ethical codes, and the goal of collegiality is to support nurses to achieve the best care for patients. Collegiality includes confidential and dialogical communication and non-hierarchical and mutual collaboration between colleagues. It is noteworthy that nurses at all levels of clinical practice, education, management, and research have shared the responsibility to support and develop nurses' collegiality. The features of nurses' collegiality that the Delphi panels most frequently agreed on concerned professional values: respect, trust, and fair treatment of colleagues, as well as courteous communication with and about colleagues. It was also highlighted that collegiality played a part in advocating for colleagues and intervening cases of colleague malpractice. The nurses' collegiality was also linked to their wellbeing at work. As a result of the Delphi process, nurses' collegiality guidelines were presented. They consist of four main themes of collegiality, and the aim of the guidelines was not only to support nurses in their clinical practice but also to provide a tool for nursing managers and teachers to help them to create the right circumstances for nurses' collegiality.

In this discussion, we will highlight four topical issues linked to our results. The first issue is that collegiality and all those values that were linked to collegiality were well-known and established values in nursing. Those values focused on nurses' mutual relationship and good collaboration. At the same time, previous studies have reported serious challenges in collegial support in professional ethics. ${ }^{1,6,10,12}$ The collegial values were also challenged due to the current prevalence of individuality at work. ${ }^{66}$ Thus, in accordance with tendencies in Western countries, nurses need to be targeted about their individual interests and career development. ${ }^{67}$ However, there was no need for adversarial relationship between individuals and collegial interests; instead collegiality proved to be an important way to support nurses during difficult times

and lack of resources. ${ }^{5}$ As with other ethical questions, collegiality also required moral courage ${ }^{68,69}$ as well as effective leadership to promote it. ${ }^{9}$ In addition, the question of the learning collegiality is crucial. In our study, participants highlighted that collegiality can be learned-especially in clinical practice, and only minority agreed that it can be taught in education. In future, more research is needed to deepen understanding of clinical nurses', managers', and educators' but also students' perceptions of how teaching of collegiality can be developed. 
The second topical issue was the main goal of nurses' collegiality. Based on our results, experts in the Delphi panel highlighted the link between collegiality and nurses' work wellbeing. Over recent decades, there has been increased interest in nurses' work wellbeing, ${ }^{70,71}$ and in this study it was rated as one of the five most important issues of collegiality. Nurses' bi-lateral, confidential relationships have been linked to the individuals' work wellbeing, but other factors such as the working environment are also important. Good relationships between nurses will help them to face ethical dilemmas. Thus, collegiality as an ethical value for professional collaboration can be argued and supported.

However, as Miller and Kontos ${ }^{39}$ described, the main goal of collaboration was not nurses and their wellbeing but patients. Collegiality is a strategy between colleagues to enhance the aims of the profession, and our results have supported that. Our experts in the Delphi panel rated that the second objective of collegiality is the patients' best interest. We think that the patient perspective can result in two consequences. The first consequence is that all values in professional working, including values like collegiality, are only argued and accepted for professional reasons, not for private interests like friendship. The second consequence is that because of the shared goal of providing the best patient care, the question of collegiality does not concern the individual's attitude or their willingness to be collegial. Instead, it can be seen as an ethical imperative for nurses to benefit from all the possible strategies to achieve the best patient care.

The third crucial issue we explored was the nature of collegiality-does collegiality refer to the intraprofessional or inter-professional relationships? Based on our results, experts in our Delphi panel rated intra-professional collegiality above inter-professional collegiality. This may partially reflect the history of the healthcare professions. The previous dominant position of physicians and their supposed strong collegiality have influenced the comprehension of the ideal characteristics of professional collegiality. Based on that history, the independence of other professions' competences, the introversion of the profession, and the advocacy of colleagues, even when things appear to go wrong, have been recognized as characteristics of a mature, collegial profession. However, current understanding of the equality of different healthcare professionals and the shared aim of healthcare can be seen to challenge the characteristics of a collegial profession. In current healthcare, the patients' care and the care results are the main aims and that presumes that all professions contribute to this. In addition, the increase in scientific knowledge means it is impossible for one profession to manage all available knowledge about a patients' care. Thus, there is a need for open, consultative, and collegial relationships between professions. The third issue is that if the shared goal is the best possible care results for patients, a collegial manner would not hide mistakes by colleagues. Therefore, there is an obvious need for both kinds of collegialities. It is crucial that different professions develop their own inter-collegiality, but that they also develop collegiality between professions.

The fourth crucial issue identified was the need for, and development of, ethical guidelines in nursing. Ethical guidelines are condensed version of professional values and ethics ${ }^{22,32}$ that aim to guide nurses in their clinical practice. Ethical guidelines, as well as professional ethics, are based on professional consensus in existing circumstances, reflecting social, cultural, and ideological principles. Instead of providing factsheets, they need to reflect nurses' existing ideologies ${ }^{63}$ and change in relation to time and society, although some core and static values and principles can be found.$^{27}$ Ethical guidelines, including the nurses' collegial guidelines, provide a tool to document professional values and to communicate about them during national and international discussion.

\section{Rigor and limitations}

The use of the Delphi panel was considered to be a suitable and effective method for developing guidelines ${ }^{48}$ and studying the ethical issues. ${ }^{46,56}$ The limitation of the method was the risk of a poor response rate. ${ }^{57}$ In our study, a relatively low number of experts were enrolled, but their responses about the items in both rounds were excellent, ranging from $89 \%$ to $100 \%$ in the first round and reaching $100 \%$ in the second round. 
This study provided guidelines based on the research process, which consisted of a systematic review of previous relevant literature and empirical knowledge by the experts in the Delphi panel. The rigor of identifying relevant published literature was ensured with method employed during the systematic review, and the whole development process was executed with the collaboration of the research group. In future, validity and the use of the guidelines need to be determined by implementing them in several nursing sites. Also the guidelines have to be tested in practice in order to find out how useful they are for management, education, and clinical practice. ${ }^{44,45,50}$ In future, longitudinal research on the practical awareness of guidelines and their use is needed.

\section{Conclusion}

Nurses' collegiality and its content have rarely been studied compared to other nursing subjects, but they are well recognized in clinical practice. As one of the core values of nurses' professional ethics, collegiality condenses the professional aim of providing the best care for patient and the significance of the ethical collaboration and communication between nurses. Current healthcare and an increased knowledge of care mean that nursing professionals and other professions need to work collegially. Nurses' collegiality can be supported by guidelines, and nurses in clinical practice, together with teachers and managers, have a shared responsibility to support and develop collegiality. However, more research in different nursing environments is needed to improve not only the understanding of the content but also the practicing of nurses' collegiality.

\section{Conflict of interests}

The author(s) declared no potential conflicts of interest with respect to the research, authorship, and/or publication of this article.

\section{Funding}

The author(s) received no financial support for the research, authorship, and/or publication of this article.

\section{References}

* Included in systematic review in the first step of the process.

1. Ulrich CM, Taylor C, Soeken K, et al. Everyday ethics: ethical issues and stress in nursing practice. $J$ Adv Nurs 2010; 66: 2510-2519.

2. Dekeyser Ganz T and Berkovitz K. Surgical nurses' perceptions of ethical dilemmas, moral distress and quality of care. $J$ Adv Nurs 2012; 68: 1516-1525.

3. Oh Y and Gastmans C. Moral distress experienced by nurses: a quantitative literature review. Nurs Ethics 2015; 22: $15-31$.

4. Wocial LD and Weaver MT. Development a psychometric testing of a new tool for detecting moral distress: the Moral Distress Thermometer. J Adv Nurs 2013; 69: 167-174.

5. Chan ES, Jones A and Wong K. The relationships between communication, care and time are intertwined: a narrative inquiry exploring the impact of time on registered nurses' work. $J$ Adv Nurs 2013; 69: 2020-2029.

6. McCarthy $\mathrm{J}$ and Gastmans $\mathrm{C}$. Moral distress: a review of the argument-based nursing ethics literature. Nurs Ethics 2015; 22: 131-152.

7. Baltimore JJ. Nurse collegiality: fact or fiction. Nurs Manage 2006; 37: 28-36.

8. Thompson EM. Team collegiality is key to patient safety. OR Nurse J 2010; 4: 5.

9. Menard K. Collegiality: through the eyes of a staff nurse. West J Nurs Res 2013; 35: 1233.

10. McCaffery R, Hayes RM, Cassell A, et al. The effect of an educational program on attitudes of nurses and medical residents towards the benefits of positive communication and collaboration. $J$ Adv Nurs 2012; 68: 293-301. 
11. Liaschenko J and Peter E. Nursing ethics and conceptualization of nursing: profession, practice and work. $J A d v$ Nurs 2004; 46: 488-495.

12. Verpeet E, Meulenbergs T and Gastmans C. Professional values and norms for nurses in Belgium. Nurs Ethics 2003; 10: 654-665.

13. Cofer M. Nursing ethics: collegiality and intergenerational differences. Virg Nurs Today 2002; 10: 10.

14. Kangasniemi M, Suutarla A, Tilander E, Haapa T and Arala K. Sairaanhoitajien kollegiaalisuus: systemaattinen kirjallisuuskatsaus [Nurses' collegiality: a systematic review]. Tutkiva Hoitotyö [Nursing Evidence] 2015; 13: $35-43$.

15. American Nurses Association (ANA). Code of ethics for nurse with interpretive statements, http://www.nursingworld.org/DocumentVault/Ethics_1/Code-of-Ethics-for-Nurses.html (2001, accessed 8 June 2015).

16. Nursing and Midwifery Board in Australia (NMBA). Code for nursing ethics in Australia, http://www.nursingmidwiferyboard.gov.au/Codes-Guidelines-Statements/Codes-Guidelines.aspx (2005, accessed 8 June 2015).

17. Finnish Nurses' Association (FNA). Sairaanhoitajien eettiset ohjeet [Code of Ethics for Nurses], https://sairaanhoitajat.fi/jasenpalvelut/ammatillinen-kehittyminen/sairaanhoitajan-eettiset-ohjeet/ (1996, accessed 8 June 2015).

18. Nursing and Midwifery Council (NMC). The Code: standards of conduct. Performance and ethics for nurses and midwives, http://www.nmc-uk.org/Documents/Standards/The-code-A4-20100406.pdf (2008, accessed 8 June 2015).

19. International Council of Nurses (ICN). The ICN code of ethics for nurses, http://www.dsr.dk/ser/Documents/icncode_english.pdf (2012, accessed 8 June 2015).

20. *Nolan MG. Wanted: colleagueship in nursing. J Nurs Adm 1976; 6: 41-43.

21. *McMahon R. Power and collegial relations among nurses on wards adopting primary nursing and hierarchical ward management structures. J Adv Nurs 1990; 15: 232-239.

22. Abbott A. Professional ethics. Am J Sociol 1983; 88: 855-885.

23. Kasher A. Professional ethics and collective professional autonomy: a conceptual analysis. Ethical Perspect 2005; 11: 67-98.

24. McCurry MK, Hunter Revell SM and Roy SC. Knowledge for the good of the individual and society: linking philosophy, disciplinary goals, theory and practice. Nurs Philos 2009; 11: 42-52.

25. Kangasniemi M, Pakkanen P and Korhonen A. Professional ethics in nursing: an integrative review. J Adv Nurs 2015; 71: 1744-1757.

26. Johnstone MJ. Professional ethics in nursing: a philosophical analysis. Aust J Adv Nurs 1987; 4: 15-21.

27. Kangasniemi M, Viitalähde K and Porkka S. A theoretical examination of the rights of nurses. Nurs Ethics 2010; 17: 628-635.

28. Frankel MS. Professional codes: why, how and with what impact? J Bus Ethics 1989; 8: 109-115.

29. Meulenbergs T, Verpeet E, Schotsmans $P$, et al. Professional codes in changing nursing context: literature review. $J$ Adv Nurs 2004; 46: 331-336.

30. Brecher B. What is professional ethics? Nurs Ethics 2014; 21: 239-244.

31. Dobrowolska B, Wronska I, Wiestaw F, et al. Moral obligations of nurses based on the ICN, UK, Irish and Polish codes of ethics for nurses. Nurs Ethics 2007; 14: 171-180.

32. Freitas L. Historical roots and future perspectives related to nursing ethics. J Prof Nurs 1990; 6: 197-205.

33. Hussey T. Nursing ethics and codes of professional conduct. Nurs Ethics 1996; 3: 250-258.

34. *Hansen HE. A model for collegiality among staff nurses in acute care. J Nurs Adm 1995; 25: 11-20.

35. *Cowan SA and Tveit LC. Collegial model for clinical nurse specialists: theoretical perspective. Clin Nurse Spec 1994; 8: 267-278.

36. *Campbell-Heider N and Pollock D. Barriers to physician-nurse collegiality: an anthropological perspective. Soc Sci Med 1987; 25: 421-425.

37. *Schmalenberg C, Kramer M, King CR, et al. Excellence through evidence: securing collegial/collaborative nurse-physician relationships, part 1. J Nurs Adm 2005; 35: 450-458. 
38. *Padgett SM. Professional collegiality and peer monitoring among nursing staff: an ethnographic study. Int J Nurs Stud 2013; 50: 1407-1415.

39. *Miller KL and Kontos PC. The intraprofessional and interprofessional relations of neurorehabilitation nurses: a negotiated order perspective. $J$ Adv Nurs 2012; 68: 1797-1807.

40. *Nørgaard B, Ammentorp J, Kofoed P-E, et al. Training improves inter-collegial communication. Clin Teach 2012; 9: $173-177$.

41. *Rubin G, Balaji RV and Barcikowski R. Barriers to nurse/nursing aide communication: the search for collegiality in a southeast Ohio nursing home. J Nurs Manag 2009; 17: 822-832.

42. *Cowin LS and Eagar SC. Collegial relationship breakdown: a qualitative exploration of nurses in acute care setting. Collegian 2012; 20: 115-121.

43. *Jackson D, Peters K, Andrew S, et al. Trial and retribution: a qualitative study of whistleblowing and workplace relationships in nursing. Contemp Nurse 2010; 36: 34-44.

44. Sasso L, Stievano A, Jurado MG, et al. Code of ethics and conduct for European nursing. Nurs Ethics 2008; 15 : 821-836.

45. Rycroft-Malone J. Formal consensus: the development of a national clinical guideline. Qual Health Care 2001; 10: 238-244.

46. Erlund M, Lindwall L, von Post I, et al. Concept determination of human dignity. Nurs Ethics 2013; 20: 851-860.

47. Hart LM, Jorm AF, Paxton SJ, et al. First aid for eating disorders. Eat Disord 2009; 17: 357-384.

48. Rolls KD and Elliot D. Using consensus methods to develop clinical practice guidelines for intensive care: the intensive care collaborative project. Aust Crit Care 2008; 21: 200-215.

49. Downs J, Bergman A, Carter P, et al. Guidelines for management of scoliosis in Rett syndrome patients based on expert consensus and clinical evidence. Spine 2009; 34: E607-E617.

50. Rolley JX, Salamonson Y, Dennison CR, et al. Development of clinical practice guidelines for the nursing care of people undergoing percutaneous coronary interventions: an Australian \& New Zealand collaboration. Aust Crit Care 2010; 23: 177-187.

51. Chami K, Gavazzi G, de Wazières LB, et al. Guidelines for infection control in nursing homes: a Delphi consensus web-based survey. J Hosp Inf 2011; 79: 75-89.

52. Sowter J, Cortis J and Clarke DJ. The development of evidence based guidelines for clinical practice portfolios. Nurs Educ Today 2011; 31: 872-876.

53. Gill FJ, Leslie GD, Grech C, et al. Using a web-based survey tool to undertake a Delphi study: application for nurse education research. Nurs Educ Today 2013; 33: 1322-1328.

54. Davis L, Taylor H and Reyes H. Lifelong learning in nursing: a Delphi study. Nurs Educ Today 2014; 34: 441-445.

55. Pechak CM and Black JD. Proposed guidelines for international clinical education in US-based physical therapist education programs: results of a focus group and Delphi study. Phys Ther 2014; 94: 523-533.

56. Ito C, Ota K and Matsuda M. Educational content in nurse education in Japan: a Delphi study. Nurs Ethics 2011; 18 : 441-454.

57. McKenna HP. The Delphi technique: a worthwhile research approach for nursing? J Adv Nurs 1994; 19: $1221-1225$.

58. Schmidt RC. Managing Delphi surveys using nonparametric statistical techniques. Dec Sci 1997; $28: 763$.

59. Linstone HA and Turoff M. The Delphi method: techniques and applications, http://is.njit.edu/pubs/delphibook/ (2002, accessed 8 June 2015).

60. Graneheim UH and Lundman B. Qualitative content analysis in nursing research: concepts, procedures and measures to achieve trustworthiness. Nurs Educ Today 2004; 24: 105-112.

61. Keeney S, Hasson F and McKenna H. Consulting the oracle: ten lessons from using the Delphi technique in nursing research. $J$ Adv Nurs 2006; 53: 205-212.

62. Wilson S, Ramelet A-S and Zuiderduyn S. Research priorities for nursing care of infants, children and adolescents: a west Australian Delphi study. J Clin Nurs 2010; 19: 1919-1928. 
63. Holland S. Scepticism about the virtue ethics approach to nursing ethics. Nurs Philos 2010; 11: 151-158.

64. Medical Research Act 1999/488, http://www.finlex.fi/fi/laki/ajantasa/1999/19990488 (accessed 8 June 2015).

65. World Medical Association (WMA). Declaration of Helsinki, http://www.wma.net/en/10home/index.html (2011, accessed 8 June 2015).

66. Tanaka S, Serizawa T and Sakaguchi C. Career redevelopment programs for inactive nurses in Japan. J Clin Nurs 2008; 17: 3296-3305.

67. Philibrick JL and Cleveland AD. Personal branding: building your pathway to professional success. Med Ref Serv $Q$ 2015; 34: 181-189.

68. Lachman VD. Moral courage: a virtue in need of development? Medsurg Nurs 2007; 16: 131-133.

69. Murray JS. Moral courage in healthcare: acting ethically even in the presence of risk. Online J Issues Nurs 2010; 15:3.

70. Utriainen K, Kyngäs H and Nikkilä J. A theoretical model of ageing hospital nurses' well-being at work. J Nurs Manag 2011; 19: 1037-1046.

71. Laschinger SHK, Nosko A, Wilk P, et al. Effects of unit empowerment and perceived support for professional nursing practice on unit effectiveness and individual nurse well-being: a time-lagged study. Int J Nurs Stud 2014; 51: 1615-1623.

72. Finnish Nurses' Association. Nurses' Collegiality Guidelines, https://sairaanhoitajat.fi/wp-content/uploads/2014/ 10/KOLLEGIAALISUUS_A4_ENG.pdf (2014, accessed 26 September 2015). 